\title{
Quantifying Intranasally Administered Deferoxamine in Rat Brain Tissue with Mass Spectrometry
}

Authors: Kosyakovsky, J; Witthuhn, BA; Svitak, AL; Frey II, WH; Hanson, LR; Fine, JM*

*corresponding author: Jared.M.Fine@,HealthPartners.com

Standard curves for deferoxamine were established using the internal standard method discussed in Methods. Briefly, standard solutions of deferoxamine and deuterated deferoxamine were analyzed in a matrix of processed brain tissue or blood serum to generate curves $A$ and $B$ respectively. Ions corresponding to all detected deferoxamine and deuterated deferoxamine analytes $(\mathrm{DFO}+\mathrm{FO}+\mathrm{AO}$ and $\mathrm{DFO}-\mathrm{d} 7+\mathrm{FO}-\mathrm{d} 7+\mathrm{AO}-\mathrm{d} 7)$ were used in the analysis. Standard curves were prepared each mass spectrometry run (daily).
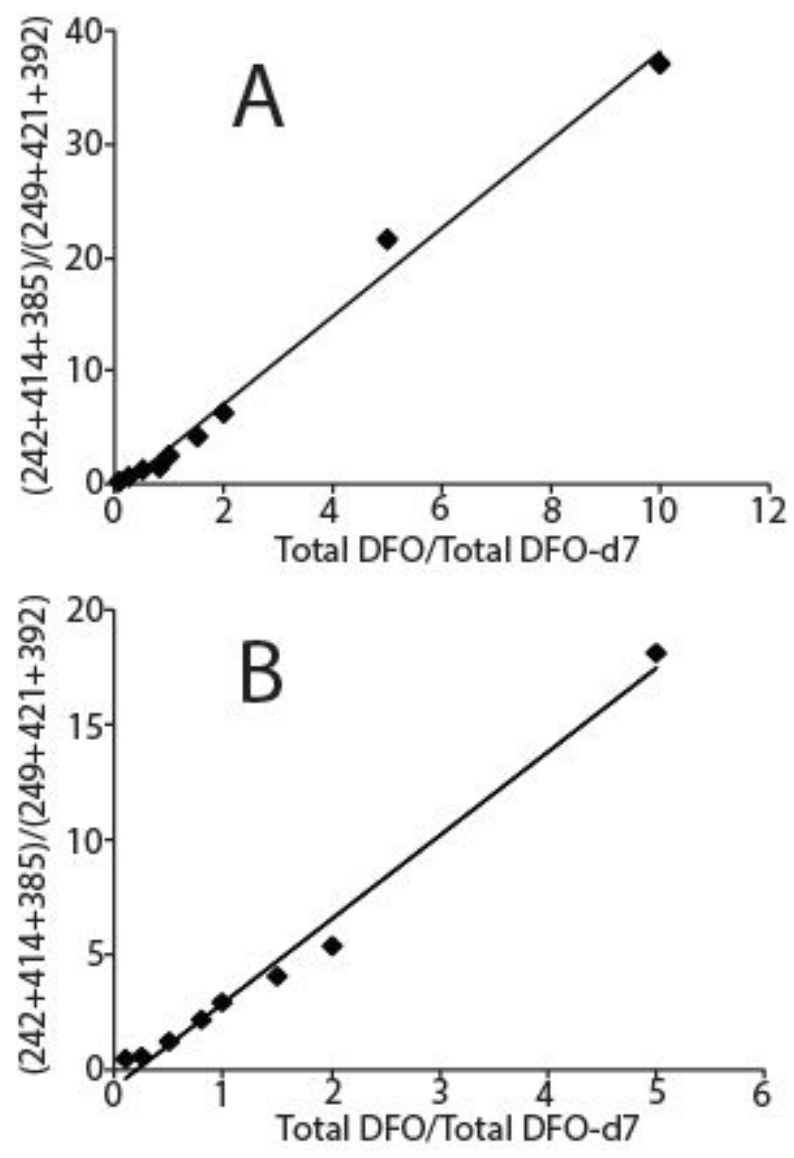

Supplemental Figure 1. Example calibration curves as used in quantitative determinations in this study. Fragments corresponding to DFO (m/z 242), FO (m/z 414), AO (m/z 385), DFO-d (m/z 249) $\mathrm{FO}_{-} d_{7}(\mathrm{~m} / \mathrm{z} 421), A O-d_{7}(\mathrm{~m} / \mathrm{z} 392)$ were monitored in each standard solution (in appropriate matrix - either processed brain homogenate $(\boldsymbol{A})$ or blood serum [B]). For calibration, the sum of the ratio of total DFO species $(\mathrm{m} / \mathrm{z} 242,414,385)$ to DFO-d $\mathrm{d}_{7} \mathrm{species}(\mathrm{m} / \mathrm{z}$ 
$249,421,392)$ was plotted as a function of the ratio of total DFO to total DFO-d 7 to yield linear curves with high linearity ( $R$-squared $=0.990$ in $\boldsymbol{A}$ and 0.985 in $\boldsymbol{B})$. 